\title{
Efficient Polymer-Supported Sharpless Alkene Epoxidation Catalyst*
}

\author{
Jaana K. Karjalainen ${ }^{a}$, Osmo E.O. Hormi ${ }^{a * *}$ and David C. Sherrington ${ }^{b}$ \\ ${ }^{\text {a}}$ Department of Chemistry, University of Oulu, Linnanmaa, P.O.Box 333, FIN-90570 Oulu, Finland \\ Fax ++(0)8-553 1603, e-mail: Jaana.Karjalainen@oulu.fi (Jaana K. Karjalainen) \\ e-mail: Osmo.Hormi@oulu.fi (Osmo E.O. Hormi)

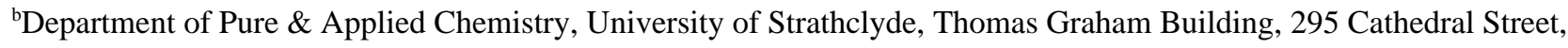 \\ Glasgow, G1 1XL, Scotland, U.K. \\ Fax ++(0)141-552 5664, e-mail: M.P.A.Smith@strath.ac.uk
}

\begin{abstract}
Homogeneous linear poly(tartrate ester) ligands provide high chemical yields and enantiomeric excesses in the epoxidation of trans-hex-2-en-1-ol using $\mathrm{Ti}\left(\mathrm{OPr}^{\mathrm{i}}\right)_{4}$-tert-butyl hydroperoxide. Branched poly(tartrate ester) can be use as heterogeneous ligands in the epoxidation of trans-hex-2-en-1-ol using $\mathrm{Ti}\left(\mathrm{OPr}^{\mathrm{i}}\right)_{4}$-tert-butyl hydroperoxide. Removal and recovery of the polymer catalyst is a simple filtration at the end of reactions.
\end{abstract}

Keywords: Asymmetric epoxidation, Sharpless epoxidation, polymer-supported catalyst

\section{Introduction}

Immobilization of reactive species on a polymer support could provide many important advantages over analogous homogeneous systems; for example separation of the support from the reaction mixture can be achieved by simple filtration aiding isolation and purification procedures, reactive species can become more active and/or more selective due to changes in the microenvironment of the active sites, excess of a polymeric reagent can be readily employed without incurring a penalty in work-up, transition metal complexes and optically active catalysts might be efficiently retained for re-use, and noxious or toxic species might be encapsulated when bound to a macromolecule, with obvious advantages in environmental terms [1]. Though the limited commercial availability and the initial extra costs do not favour the use of polymer supports, the numerous advantages are well recognised [1]. Unfortunately in the case of asymmetric catalysts the supported systems often suffer from a significant drop in enantioselectivity compared to the corresponding low molecular weight species [2]. Recently attention has focused on polymersupported asymmetric alkene oxidation catalysts [3]. Interestingly, there are no reports of the successful immobilisation of the Sharpless Ti-tartrate ester-based asymmetric alkene epoxidation catalyst, despite this being a relatively long-standing and well used methodology. Some approaches to the production of a heterogeneous Sharpless-type epoxidation catalyst have been reported, but the level of asymmetric induction achieved was generally only modest [4].

We have previously reported on the synthesis of a group of poly(tartrate ester) ligands and their use with

\footnotetext{
* Part of this paper was presented at ECSOC-1, http://www.mdpi.org/ecsoc-1.htm, 1- 30 September 1997.
}

** To whom correspondence should be addressed. 
titanium tetraisopropoxide and tert-butyl hydroperoxide (tBHP) as the oxidant in epoxidising trans-hex-2-en-1-ol in high chemical yield and with good enantioselectivity [5]. Although the enantiomeric excesses are in general a little lower than those achieved using monomeric tartrate esters, they are still significantly better than those from previously reported polymer-supported systems [4]. We believe therefore that our results are important in methodological and potentially technological terms, and offer the prospect of new information regarding the structure of the active species and its mechanistic role.

We have also synthesized in common organic solvents insoluble branched and/or crosslinked poly(tartrate ester)s and have studied the use of both homogeneous and heterogeneous optically active poly(tartrate ester) ligands in asymmetric epoxidations of a number of trans-allylic alcohols with titanium tetraisopropoxide and tBHP [6]. We have investigated the effect of the ratio of polymer ligand to titanium on the enantioselectivity and the yields, and the influence of the polymer backbone molecular architecture on asymmetric induction.

\section{Results and Discussions}

In a recent communication we described the synthesis of linear optically active polyesters which were obtained by bulk or phase transfer catalysed polycondensation of diacids with diols [5]. We have now developed the bulk polymerisation further. In general, it is difficult to prepare polyesters having pendant functional groups such as hydroxyl groups on a mainchain by melt polycondensation since the pendant groups participate in the reaction leading to crosslinking [7].

However, according to the ${ }^{1} \mathrm{H}$ NMR spectra of the products no branching/crosslinking was observed [8]. We therefore started our studies to evaluate the possibility of mimicing the Sharpless procedure using these linear soluble optically active polymers as ligands to achieve efficient and enantioselective catalysis. From the results obtained in a preliminary study of the epoxidation of transhex-2-en-1-ol, we hoped that the synthesis of similar but heterogeneous polymer systems would be also possible. Accordingly we have now synthesized some branched/crosslinked optically active polyesters using elevated reaction temperature and prolonged reaction time [6].

\section{Optically active poly(tartrate ester)s}

Poly(tartrate ester)s 3a-3d were synthesized from L(+)-tartaric acid 1, diols 2 and 3 w- $\%$ p-toluene sulphonic acid as a catalyst using a standard polycondensation procedure, as shown in Scheme 1 [9]. Poly(tartrate ester)s 3e-3f were synthesized from L-(+)-tartaric acid disodium salt dissolved in water and $\alpha, \alpha^{\prime}$-dichloroxylene dissolved in $\mathrm{CHCl}_{3}$ by a phase transfer catalyzed procedure using tetrabutylammonium bromide hydrate (TBAB) as the catalyst as shown in Scheme 2 [10]. Polymers 3a-f dissolved in some organic solvents, for example in $\mathrm{Me}_{2} \mathrm{SO}$ and therefore the optical rotation could be measured. All the polymers display a positive optical rotation. Since the observed values are comparable to those reported for dimethyl-L-(+)-tartrate and for diethyl-L-(+)-tartrate [11], it seems that no significant racemization occurs during the various polymerization procedures. Solubility limitations have made molecular weight determination difficult, but two different batches of 3d yielded $\mathrm{Mw}=4150$ and 4210, with $\mathrm{M}_{\mathrm{w}} / \mathrm{M}_{\mathrm{N}}=1.7$ by gel permeation chromatography using polystyrene standards in THF. Table 1 gives the relevant data for the synthesis and characterisation of polyesters 3a-f.

The branched/crosslinked $\mathrm{C}_{8}$-alkyl group-containing poly(tartrate ester) gel 4 was synthesized from L-(+)tartaric acid 1, 20 mol-\% excess of 1,8-octanediol $\mathbf{2 c}$ and 3 $\mathrm{w}-\%$ p-toluene sulphonic acid as a catalyst, as shown in Scheme 3 [9]. The conditions used were anaerobic and more forcing than with $\mathbf{3 c}$, and this seems to be the orgin of the branching/crosslinking. Most of the polymer batches were soluble either in hot pyridine, hot THF or hot $\mathrm{Me}_{2} \mathrm{SO}$. All the polymers which were soluble in hot THF, displayed a positive optical rotation [12].

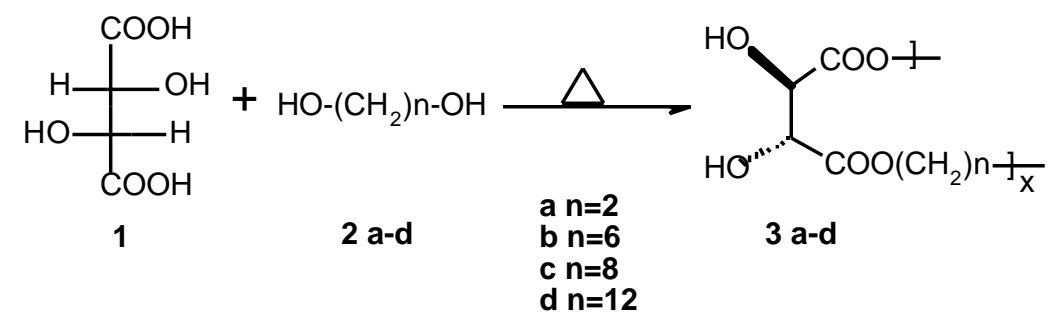

Scheme 1. Reagents and conditions: toluene-p-sulfonic acid ( 3 mass $\%), c a .120^{\circ} \mathrm{C}, 3$ days. 


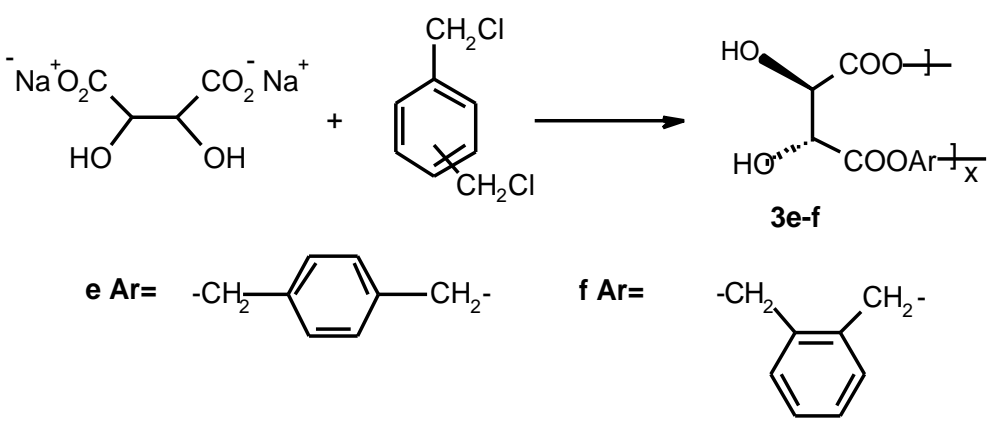

Scheme 2. Reagents and conditions: $\mathrm{Bu}_{4} \mathrm{NBr}(20 \mathrm{~mol} \%), \mathrm{H}_{2} \mathrm{O}, \mathrm{CHCl}_{3}$, reflux, 7 days.

Table 1 Synthesis of polyesters 3 .

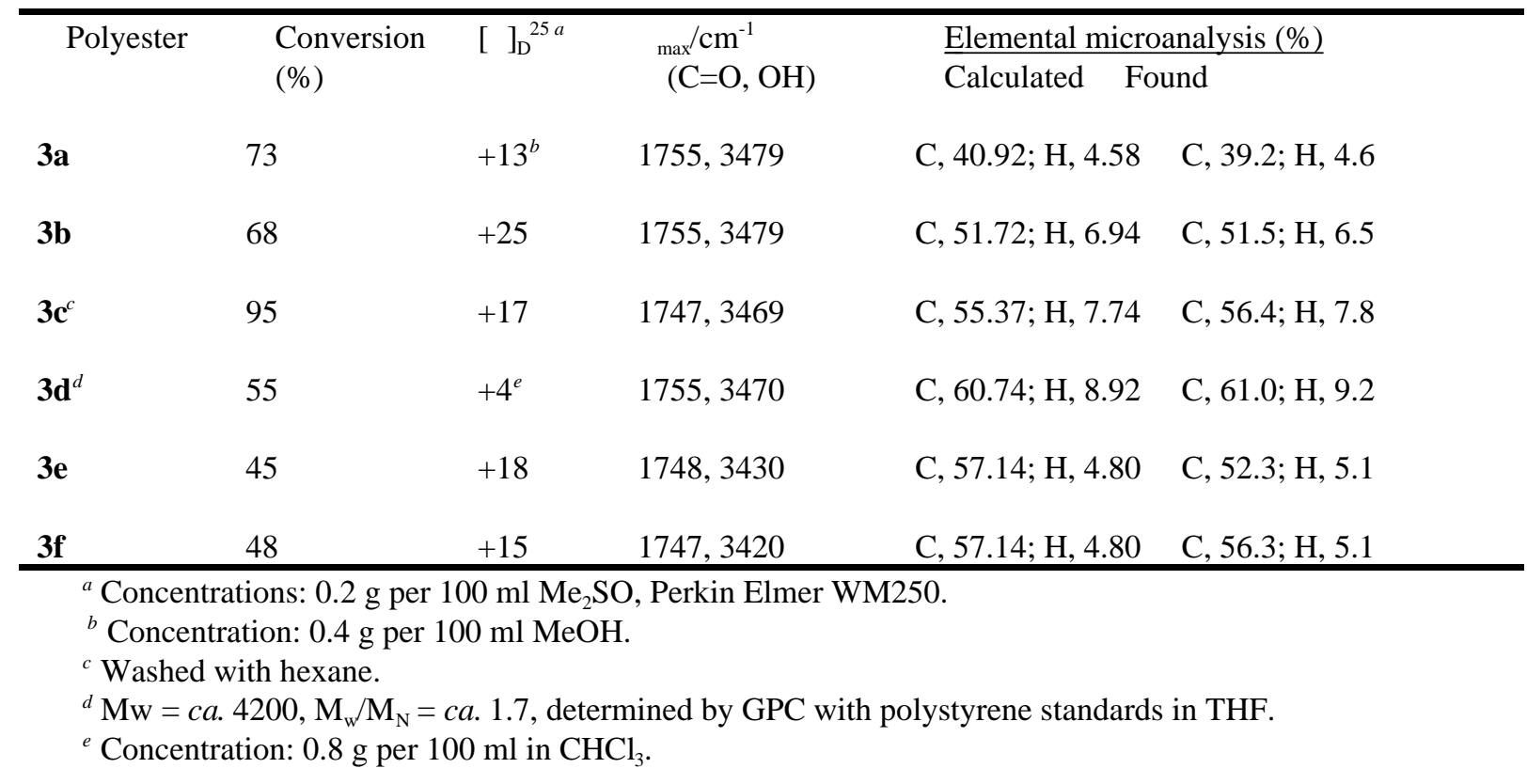

\section{Asymmetric epoxidation of trans-hex-2-en-1-ol using homogeneous poly(tartrate ester)s ligands}

The results for epoxidation reactions of trans-hex-2-en1-ol are summarized in Table 2. Poly(tartrate ester) ligands 3a-f formed $\mathrm{CH}_{2} \mathrm{Cl}_{2}$ soluble complexes with titanium tetraisopropoxide and tert-butylhydroperoxide and thus could not be filtered off at the end of the reaction [13]. It was expected that these homogeneous systems would react like low molar mass dimethyl- and diethyltartrates since the reactants and the soluble catalysts are uniformly distributed throughout the reaction medium [14]. In practice reactions were somewhat slower with the polymer ligands than with the low molar mass esters, and so the ligand/substrate ratios and $\mathrm{Ti} /$ substrate ratios used were somewhat higher.

Sharpless et al. [15] have shown that by adding molecular sieves in the epoxidation of trans-hex-2-en-1-ol, using 5/6 \% Ti/diethyl-L-(+)-tartrate as the catalyst, reaction rates are roughly twice as fast as without sieves, the main function of the sieves being protection of the catalyst from adventitious water in the reaction medium [16]. All our reactions were therefore performed using molecular sieves. Conversions were monitored using GC, and the reactions were stopped when the conversions were over $60 \%$. In general, the conversion of this allylic alcohol to epoxide is good (up to $92 \%$ ) and comparable to the value obtained with dimethyl tartrate. The isolation procedure has not however been fully optimised and it was 
noticed that isolated yields sometimes exceeded the GC yields presumably reaction continued in the freezer overnight [17]. Enantiomeric excesses depend on the poly(tartrate ester) employed (Table 2.) and interestingly varied from 8 to $79 \%$ generally with good chemical yields. Polymer 3a containing the ethylene group in the backbone is a poor ligand, yielding essentially racemic epoxide ( 8 ee\%). Polymer $\mathbf{3 b}$ having the $\mathrm{C}_{6}$-alkyl group was thus prepared but quite low asymmetric induction was still observed. The highest enantioselectivity (79 ee\%) was attained using polymer $3 \mathbf{c}$ having the flexible $\mathrm{C}_{8}$-alkyl group between respect tartrate residues. In addition, polymer 3d with the $\mathrm{C}_{12}$-alkyl group also gave good asymmetric induction (41-77 ee\%) the result depending strongly on the ratio of ligand to titanium used. These results demonstrate that the $\mathrm{C}_{8}$-alkyl group is long enough to improve the accessibility of $\mathrm{Ti}$ to the functional groups and to allow the polymer to adopt the necessary conformation for formation of the active catalytic complex [18]. The longer $\mathrm{C}_{12}$-alkyl chains did not further enhance the level of induction.

Two polymers containing aromatic groups in the backbone were also prepared. The results of epoxidations using these ligands were as expected. The backbone with a non-linear structure arising from the ortho substituted aromatic segment gave a better asymmetric induction than that from the more linear polymer derived from para substituted aromatic component. Intuitively we felt that the less linear chain would offer more opportunity for adjacent or nearly tartrate ester groups to form the appropriate catalytic complex with Ti. Currently we are pursuing molecular modelling studies to develop these arguments more fully.
It is well established [19] that the Sharpless dialkyl tartrate- $\mathrm{Ti}\left(\mathrm{O}^{\mathrm{i}} \mathrm{Pr}\right)_{4}$ complex has a 2:2 dimeric structure. Thus a ligand:Ti ratio of $\sim 1: 1$ tends to give the highest enantiomeric excesses. In practice it is common to use a 10 $\%$ excess of ligand to $\mathrm{Ti}$ to ensure full complexation, beyond this, excess tartrate can result in slower epoxidation [19].

The best ratio of polymer ligand to obtain highest enantioselectivity depended to some extent on the polymer ligand employed. Generally the optimium value was 1.18:1; however this was not always the case. For example with polymer ligand 3d a polymer ligand:Ti ratio of 3:1 gave an ee\% of 77 .

Overall the polymer ligand which performed best was 3c with the $\mathrm{C}_{8}$-alkyl group segment, and so it was decided to examine this species in more detail to produce a fully heterogeneous analogue.

\section{Asymmetric epoxidation of trans-hex-2-en-1-ol using heterogeneous poly(tartrate ester) ligands}

Polymer-ligand 4 did not form $\mathrm{CH}_{2} \mathrm{Cl}_{2}$ soluble complexes with $\mathrm{Ti}\left(\mathrm{O}^{\mathrm{i}} \mathrm{Pr}\right)_{4}$. Inevitably between $70-100 \%$ of polymer was recovered from reaction mixtures by simple filtration. The polymer was washed thoroughly with $\mathrm{CH}_{2} \mathrm{Cl}_{2}$ and dried under vacuum at room temperature. IR spectroscopic analysis showed the polymer to have the same characteristic bands at $3400-3500 \mathrm{~cm}^{-1}$ and $1750 \mathrm{~cm}^{-1}$ as before the reaction, indicating that in principle the polymer ligand might be reused [20]. The results of epoxidations of trans-hex-2-en-1-ol are summarized in Table 2.

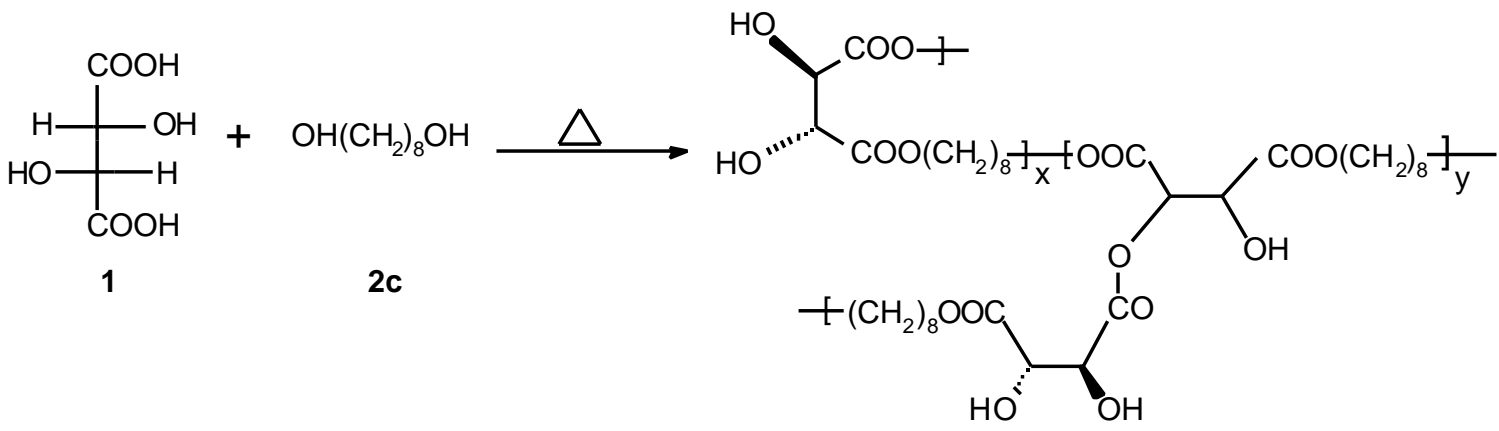

Scheme 3. Reagents and conditions: toluene-p-sulfonic acid (3 mass \%), 20 mol\% excess of diol $2 c, c a .130{ }^{\circ} \mathrm{C}, 4 \mathrm{~d}$. 


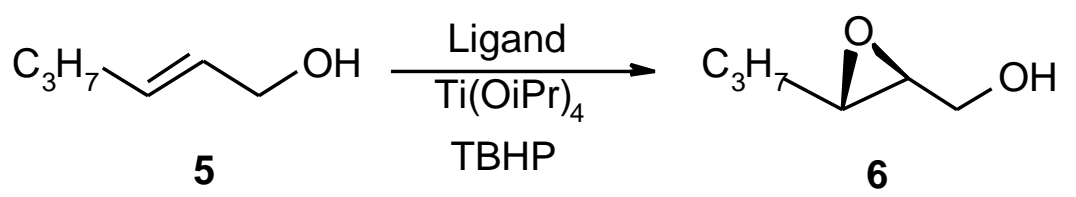

Scheme 4. Reagents and conditions: poly(tartrate ester), $\mathrm{Ti}\left(\mathrm{OPr}^{\mathrm{i}}\right)_{4}, \mathrm{Bu}^{\mathrm{t}} \mathrm{OOH}(2$ equiv. $), 4 \AA$ molecular sieves, $\mathrm{CH}_{2} \mathrm{Cl}_{2}$.

Table 2. Epoxidation of trans-hex-2-en-1-ol 5 with tBHP by L-(+)-polyester 3a-f/4 and $\operatorname{Ti}\left(\mathrm{OPr}^{\mathrm{i}}\right)_{4}$ at $-20^{\circ} \mathrm{C}(\mathrm{Scheme} 4)$.

\begin{tabular}{|c|c|c|c|c|c|}
\hline Ligand & $\begin{array}{l}\text { Molar ratio } \\
\text { 5:Ti:tartrate }\end{array}$ & $\begin{array}{l}\text { Reaction } \\
\text { time } / h^{a}\end{array}$ & $\begin{array}{l}\text { Epoxide yield } \\
(\%), \mathrm{GC}^{b}\end{array}$ & $\begin{array}{l}\text { Isolated yield } \\
(\%)^{c}\end{array}$ & $\mathrm{Ee} \%^{e}$ \\
\hline $\begin{array}{c}\text { 3a } \\
\text { Homoen }\end{array}$ & $100: 17: 20$ & 3 & 51 & 50 & 8 \\
\hline $\begin{array}{c}\mathbf{3 b} \\
\text { Homogen. }\end{array}$ & $100: 17: 20$ & 3 & 63 & 63 & 55 \\
\hline $\begin{array}{c}\mathbf{3 c} \\
\text { Homogen. }\end{array}$ & $100: 5: 10$ & 3 & 22 & 59 & 79 \\
\hline $\begin{array}{c}\mathbf{3 c} \\
\text { Homogen. }\end{array}$ & $100: 17: 20$ & 7 & 92 & 58 & 79 \\
\hline $\begin{array}{c}\mathbf{4} \\
\text { Heterogen. }\end{array}$ & $100: 40: 50$ & 6 & 88 & $72^{d}$ & $72^{f}$ \\
\hline $\begin{array}{c}\mathbf{4} \\
\text { Heterogen. }\end{array}$ & $100: 25: 50$ & 6 & 87 & $53^{d}$ & $87^{f}$ \\
\hline & 100:10:30 & 3 & 80 & 61 & 77 \\
\hline $\begin{array}{c}\mathbf{3 d} \\
\text { Homogen. }\end{array}$ & $100: 17: 20$ & 3 & 75 & 61 & 64 \\
\hline $\begin{array}{c}\mathbf{3 e} \\
\text { Homogen. }\end{array}$ & 100:17:20 & 3 & 73 & 42 & 47 \\
\hline $\begin{array}{c}\text { 3f } \\
\text { Homogen. }\end{array}$ & $100: 17: 20$ & 3 & 74 & 80 & 68 \\
\hline
\end{tabular}

${ }^{a}$ From addition of $\mathbf{5}$.

${ }^{b}$ From GC analysis.

${ }^{c}$ After additional $12 \mathrm{~h}$ in freezer, work-up and Kugelrorh-distillation.

${ }^{d}$ After additional $12 \mathrm{~h}$ in freezer, work-up and Flash-chromatography.

${ }^{e}$ ee\% determined via chiral HPLC (Chiralcel OB, hexane-Pri ${ }^{\mathrm{i}} \mathrm{OH}$ ).

${ }^{f}$ ee\% determined by ${ }^{1} \mathrm{H}$ NMR Shift analysis of the derived acetate with $\mathrm{Eu}(\mathrm{hfc})_{3}$ in benzene- $\mathrm{d}_{6}$.

\section{Conclusion}

The first successful polymer-supported Sharpless-type epoxidation catalyst has been developed. Several oligomeric linear poly(tartrate ester)s ligands have been used homogeneously in the epoxidation of trans-hex-2-en1-ol with titanium tetraisopropoxide and tert-butyl hydroperoxide as the oxidant. These ligands provide high chemical yields and good enantioselectivities, comparable to the monomeric catalytic system. The highest enantioselectivity (79 ee\%) was attained using polymer $\mathbf{3 c}$ having a flexible $\mathrm{C}_{8}$-spacer between the functional hydroxyl groups. The nature of the complex with $\mathrm{Ti}$ (intramolecular vs. intermolecular) is now being studied by molecular modelling.

Preliminary results indicate that the branched poly(tartrate ester) 4 can be used successfully as a heterogeneous ligand in the epoxidation of trans-hex-2-en- 
1-ol. Surprisingly the chemical yields and enantiomeric excesses were even higher than when using oligomeric polymer ligands (up to 87 ee\%). Removal and recovery of the polymer catalyst is a simple filtration at the end of the reactions which remarkably facilitates the work-up procedure.

\section{Experimental Section}

\section{General}

The ${ }^{1} \mathrm{H}$ NMR and ${ }^{13} \mathrm{C}$ NMR spectra were obtained on a Bruker AM200 MHz or Bruker DPX400 $\mathrm{MHz}$ spectrometers. Chemical shifts $(\boldsymbol{\delta})$ are given in ppm relative to TMS. Gas chromatographic (GC) analysis were carried out on Carlo Erba GCHR 5300 Mega Series employing a SGE BPX5 column or Perkin Elmer 8500 equipped with FID detector employing a 25-m packed with fused silica column (phase layer $0.25 \mu \mathrm{m}$ ). FTIR spectra were measured on a Bruker IFS 66- or Nicolet Impact 400d-instruments, wawenumbers are in $\mathrm{cm}^{-1}$. Enantiomeric ratios measured by HPLC were determined using a Daicel Chiralcel OB column (flow rate $=0.5 \mathrm{ml} / \mathrm{min}$, hexane/isopropanol $=97.5-2.5)$. High resolution GC/MS analysis were performed by the Mass Spectrometry Laboratory of the University of Oulu, Finland. Optical rotations were determined on Perkin-Elmer WM250 or Perkin-Elmer 243 B polarimeters using a $1-\mathrm{cm}^{3}$ capacity, 1 $\mathrm{dm}$ path length, quartz cell. Elemental analyses were performed by the Microanalytical Laboratory of the University of Strathclyde, Scotland or by the Microanalytical Laboratory of the University of Oulu, Finland. Molecular weights were measured by gel permeation chromatography (polystyrene standards in THF) by RAPRA, UK. Flash chromatography was performed using Merck Silica gel 60 (230-400 mesh) with diethyl ether/petrol ether $\left(40^{\circ} \mathrm{C}-60^{\circ} \mathrm{C}\right)$ in various proportions as eluent. Absolute configurations were determined by comparison of the observed rotation by polarimetry with the literature value. General preparation and shift study analysis of acetates followed the procedure described in reference 15 .

\section{Materials}

Pre-activated and powdered $4 \AA$ molecular sieves were available from Aldrich Chemical Co. and they were used as received. Cooling was accomplished through the use of the following bath: acetone/liquid nitrogen. The dichloromethane used did not contain methanol and therefore was not distilled but was stored over $\mathrm{CaCl}_{2}$. Aqueous $70 \%$ tert-butyl hydroperoxide (TBHP) was obtained from the Aldrich Chemical Co. Preparation and molarity determination of anhydrous TBHP followed the procedure described in reference 21 . Reagents handled by syringe were measured by weight or by volume.

\section{General work-up procedure}

The work-up followed the literature procedure [15] with slight modifications. The work-up procedure is described for reactions utilizing $0.1 \mathrm{~mol}$ of substrate, $3.0 \mathrm{~g}$ of sieves, $5 \mathrm{mmol}$ of $\mathrm{Ti}(\mathrm{O}-\mathrm{i}-\mathrm{Pr})_{4}, 6 \mathrm{mmol}$ of tartrate and 0.2 mol of TBHP. The amounts were scaled proportionally.

The cold $\left(-20^{\circ} \mathrm{C}\right)$ reaction mixture was quenched with a $30 \%$ aqueous solution of sodium hydroxide saturated with sodium chloride. After $10 \mathrm{w}-\%$ of diethyl ether was added, the cold bath was removed and the stirred mixture was allowed to warm to $10{ }^{\circ} \mathrm{C}$. Stirring was maintained for an additional $10 \mathrm{~min}$ at $10{ }^{\circ} \mathrm{C}$, whereupon $\mathrm{MgSO}_{4}$ and Celite were added. After a final $15 \mathrm{~min}$ of stirring, the mixture was allowed to settle and the solution was filtered through a pad of Celite and washed with diethyl ether. Excess of TBHP was removed by azeotropic distillation with toluene.

\section{Linear Optically Active Polyesters 3d}

An oven-dried $100 \mathrm{ml}$ three-necked round-bottomed flask equipped with a magnetic stir-bar was charged with L-(+)-tartaric acid (5 g, $0.033 \mathrm{~mol}), 1,12$-dodecanediol $(6.74 \mathrm{~g}, 0.033 \mathrm{~mol})$ and $\sim 3 \mathrm{w}-\% \mathrm{p}$-toluene sulphonic acid $(0.3 \mathrm{~g})$. The reaction mixture was stirred at $120{ }^{\circ} \mathrm{C}$ for 3 days. Water and unreacted diol were removed by distillation under high vacuum at the end of reaction. The resulting solid was crushed, washed with acetone/hexane in a Soxhlet apparatus for ca. 16-20 hours and dried in vacuum oven $\left(50^{\circ} \mathrm{C}\right)$ for $c a .15$ hours to yield $5.70 \mathrm{~g}, 55 \%$ $\mathrm{C}_{12}$-poly(tartrate ester) 3d.

FTIR (KBr) 3470, 3308, 2916, 2849, 1755, 1722, 1468 , $1287,1195,1132,1070,971 .{ }^{1} \mathrm{H}$ NMR $(400 \mathrm{MHz}, \mathrm{DMSO}-$ $\left.\mathrm{d}_{6}, 70{ }^{\circ} \mathrm{C}\right) \delta 4.36(\mathrm{~s}, 2 \mathrm{H}), 4.09(\mathrm{t}, J=6.6 \mathrm{~Hz}, 4 \mathrm{H}), 1.59(\mathrm{~m}$, $4 \mathrm{H}), 1.30(\mathrm{~m}, 16 \mathrm{H}) .{ }^{13} \mathrm{C} \mathrm{NMR}\left(400 \mathrm{MHz}, \mathrm{DMSO}_{-}, \mathrm{d}_{6},{ }^{\circ} \mathrm{C}\right)$ $\delta$ 171.1, 72.5, 64.5, 60.8, 28.8, 28.5, 28.1, 25.2.

Polymers 3 a-c were obtained analogously (Table 1).

Preparation of linear optically active polyesters containing aromatic spacer $3 f$

An oven-dried $100 \mathrm{ml}$ three-necked round-bottomed flask equipped with a magnetic stir-bar and a reflux condenser was charged with $5 \mathrm{~g}$ of $\mathrm{L}-(+)$-tartaric acid disodium salt $(0.022 \mathrm{~mol})$ dissolved in $10 \mathrm{ml}$ of water, 3.8 $\mathrm{g}$ of $\alpha, \alpha^{\prime}$-dichloro- $o$-xylene $(0.022 \mathrm{~mol})$ dissolved in $20-$ $30 \mathrm{ml}$ of chloroform and $\sim 20$ mol-\% tetrabutyl ammonium bromide hydrate $(1.42 \mathrm{~g}, 0.0044 \mathrm{~mol})$ as a phase transfer catalyst. The reaction mixture was reflux for 7 days. Solvents were evaporated to dryness and white solid was washed with hot water and diethyl ether and dried in a vacuum oven $\left(+50{ }^{\circ} \mathrm{C}\right)$ for 2 days to yield $2.65 \mathrm{~g}, 48 \%$ 
poly(tartrate ester) 3f. FTIR (KBr) 3545, 3394, 2967, 2873, 1747, 1445, 1421, 1374, 1290, 1266, 1225, 1128, 1089, 970, 818, 677. ${ }^{1} \mathrm{H}$ NMR (400MHz, DMSO-d $\left.6,70{ }^{\circ} \mathrm{C}\right) \delta$ $7.39(\mathrm{~m}, 4 \mathrm{H}), 5.21(\mathrm{~s}, 4 \mathrm{H}), 4.56(\mathrm{~s}, 2 \mathrm{H}) .{ }^{13} \mathrm{C}$ NMR $\left(400 \mathrm{MHz}, \mathrm{DMSO}-\mathrm{d}_{6}, 70{ }^{\circ} \mathrm{C}\right) \delta 170.10,128.82,128.62$, 127.86, 127.70, 72.21, 65.78.

Polymer 3e was obtained analogously (Table 1).

\section{Preparation of branched/crosslinked optically active polyester 4}

An oven-dried $100 \mathrm{ml}$ three-necked round-bottomed flask equipped with a magnetic stirbar, nitrogen inlet and bubbler was charged with L-(+)-tartaric acid (10 g, 0.067 mol), 20 mol- $\%$ excess of 1,8-octane diol (11.67 g, $0.07996 \mathrm{~mol})$ and $\sim 3 \mathrm{w}-\% \mathrm{p}$-toluene sulphonic acid (0.6 g). Temperature was raised to $140-150{ }^{\circ} \mathrm{C}$ to get a homogeneous mixture and then stirred at $120-130{ }^{\circ} \mathrm{C}$ for 3 4 days under nitrogen. Water and unreacted diol were removed by distillation under high vacuum at the end of reaction. The resulting solid was swelled by refluxing in ethyl acetate and then poured in $n$-hexane. The solvents were decanted and the polymer dried in high vacuum at + $40^{\circ} \mathrm{C}$ for 6 hours and at room temperature for 2 days to yield $16.6 \mathrm{~g}, 95 \%$ of $\mathrm{C}_{8}$-poly(tartrate ester) $4 .[\alpha]_{\mathrm{D}}{ }^{25}+9^{\circ}$ (c 1.6, THF). FTIR (KBr) 3450, 2932, 2857, 1743, 1466, 1395, 1128, 1091, 1011, 956. Anal. Found: C, 55.26; H, 8.47. ${ }^{1} \mathrm{H}$ NMR $\left(400 \mathrm{MHz}, \mathrm{DMSO}-\mathrm{d}_{6}, 70{ }^{\circ} \mathrm{C}\right) \delta 5.75$ (br s), $5.41(\mathrm{~d}, J=3.15 \mathrm{~Hz}), 4.62(\mathrm{~d}, J=2.83 \mathrm{~Hz}), 4.37(\mathrm{~s}, 2 \mathrm{H})$, 4.09 (t, $J=6.49 \mathrm{~Hz}, 4 \mathrm{H}), 1.58(\mathrm{~m}, 4-5 \mathrm{H}), 1.30(\mathrm{~m}, 9 \mathrm{H}) .{ }^{13} \mathrm{C}$ NMR (400MHz, DMSO-d $\left.\mathrm{d}_{6}, 70{ }^{\circ} \mathrm{C}\right) \delta 172.42(\mathrm{~s}), 171.28$ (s), $171.03(\mathrm{~s}), 80.41\left(\mathrm{~d}, J^{C H}=142.04 \mathrm{~Hz}\right), 73.45,72.45$, $72.19\left(\mathrm{~d}, J^{\mathrm{CH}}=146.24 \mathrm{~Hz}\right), 64.47\left(\mathrm{t}, J^{C H}=147.2 \mathrm{~Hz}\right)$, $28.32\left(\mathrm{t}, J^{C H}=125.64 \mathrm{~Hz}\right), 28.04\left(\mathrm{t}, J^{C H}=125.92 \mathrm{~Hz}\right)$, $25.07(\mathrm{t}, J=125.66 \mathrm{~Hz})$.

\section{General procedure for the catalytic asymmetric epoxidation using homogeneous polymer-ligand}

The literature procedure [15] for the epoxidation of allylic alcohols was followed with modifications. An ovendried three-necked round-bottomed flask equipped with a magnetic stir-bar, nitrogen inlet, septum and bubbler was charged with $4 \AA$ powdered, activated molecular sieves, polymer-ligand 3 and dry $\mathrm{CH}_{2} \mathrm{Cl}_{2}$. The flask was cooled to $-20{ }^{\circ} \mathrm{C}$ and $\mathrm{Ti}(\mathrm{O}-\mathrm{i}-\mathrm{Pr})_{4}$ (via syringe) was added sequentially with stirring. The reaction mixture was stirred at $-20{ }^{\circ} \mathrm{C}$ and after about one hour 2 equiv. of TBHP in iso-Octane was added with a syringe at a moderate rate. The resulting mixture was stirred at $-20{ }^{\circ} \mathrm{C}$ at least for hour. Substrate (dissolved in dry $\mathrm{CH}_{2} \mathrm{Cl}_{2}$ ) was added dropwise with a syringe, being careful to maintain the reaction temperature between $-15{ }^{\circ} \mathrm{C}$ and $-20{ }^{\circ} \mathrm{C}$. The mixture was stirred for an additional 3-7 hours at $-15{ }^{\circ} \mathrm{C}$ to $-20{ }^{\circ} \mathrm{C}$ and the yield was determined using gas chromatographic analysis. The reaction mixture was stored in a freezer overnight, the GC yield was then determined and work-up was performed. The crude product was purified by Kugelrorh-distillation and the enantiomeric purity of the epoxide was measured by chiral HPLC analysis.

(2S-trans)-3-Propyloxiranemethanol (6)

The epoxidation was performed as described above. $\mathrm{C}_{8}$ poly(tartrate ester) 3c (0.52 g, $0.002 \mathrm{~mol})$ was swelled in $30 \mathrm{ml}$ of $\mathrm{CH}_{2} \mathrm{Cl}_{2}$ containing $0.6 \mathrm{~g}$ of powdered, activated $4 \AA$ molecular sieves. $\mathrm{Ti}\left(\mathrm{OPr}^{\mathrm{i}}\right)_{4}(0.28 \mathrm{~g}, 0.001 \mathrm{~mol}), 10.1$ $\mathrm{ml}$ of a $3.97 \mathrm{M}$ solution of TBHP in iso-Octane and $2 \mathrm{~g}$ $(0.020 \mathrm{~mol})$ of trans-hex-2-en-1-ol (dissolved in $10 \mathrm{ml}$ $\mathrm{CH}_{2} \mathrm{Cl}_{2}$ ) were added. The reaction mixture was stirred at $20{ }^{\circ} \mathrm{C}$ for $3 \mathrm{~h}$. The reaction mixture was stored at $-20{ }^{\circ} \mathrm{C}$ over the weekend. Workup was then performed and crude product was purified by Kugelrorh-distillation to give a colourless oil 5 (1.36 g, $59 \%$ yield, $91 \%$ purity, $79 \%$ ee by HPLC, Chiralcel OB column): $[\alpha]^{25}{ }_{\mathrm{D}}-32^{\circ}(c$ 1.95, $\mathrm{CHCl}_{3}$ ), GC analysis after $3 \mathrm{~h}$ : $22 \%$ epoxide, $\mathrm{GC}$ analysis before work-up: $61 \%$ epoxide. FTIR $\left(\mathrm{CHCl}_{3}\right)$ 3030, 3013, 2977, 2952, 2883, 2856, 1237, 1196, 1083, 1029, 938, 879. ${ }^{1} \mathrm{H}$ NMR $\left(200 \mathrm{MHz}, \mathrm{CDCl}_{3}\right) \delta 3.82(\mathrm{dd}, J=2,13 \mathrm{~Hz}, 1 \mathrm{H})$, $3.53(\mathrm{dd}, J=2,13 \mathrm{~Hz}, 1 \mathrm{H}), 2.91-2-83(\mathrm{~m}, 2 \mathrm{H}), 2.68$ (s, $1 \mathrm{H}), 1.55-1.43(\mathrm{~m}, 4 \mathrm{H}), 0.90(\mathrm{t}, J=7 \mathrm{~Hz}, 3 \mathrm{H})$. MS (EI, $\mathrm{m} / \mathrm{z}$, relative intensity) $99(2, \mathrm{M}-17)^{+}, 81(13), 73$ (48), 55 (100), 43 (36). HRMS (EI) Calcd for $\mathrm{C}_{6} \mathrm{H}_{12} \mathrm{O}_{2}$ 116.0837, found 116.0832 .

\section{General procedure for the catalytic asymmetric epoxidation using heterogeneous polymer-ligand}

The literature procedure [15] for the epoxidation of allylic alcohols was followed with modifications. An ovendried three-necked round-bottomed flask equipped with a magnetic stirbar, nitrogen inlet, septum and bubbler was charged with $4 \AA$ powdered, activated molecular sieves, polymer-ligand 4 and dry $\mathrm{CH}_{2} \mathrm{Cl}_{2}$. The flask was cooled to $-20^{\circ} \mathrm{C}$ and $\mathrm{Ti}(\mathrm{O}-\mathrm{i}-\mathrm{Pr})_{4}$ (via syringe) was added sequentially with stirring. The reaction mixture was stirred at $-20{ }^{\circ} \mathrm{C}$ and after about one hour 2 equiv. of TBHP in iso-Octane was added with syringe at a moderate rate. The resulting mixture was stirred at $-20{ }^{\circ} \mathrm{C}$ at least for one hour. Substrate (dissolved in dry $\mathrm{CH}_{2} \mathrm{Cl}_{2}$ ) was added dropwise with a syringe, being careful to maintain the reaction temperature between $-15^{\circ} \mathrm{C}$ and $-20^{\circ} \mathrm{C}$. The mixture was stirred for an additional $3-12$ hours at $-15^{\circ} \mathrm{C}$ to $-20^{\circ} \mathrm{C}$. The reaction mixture was stored in a freezer up to weeks. The reaction was monitored by gas chromatography (GC) using dodecane as a GC internal standard. The polymer was filtered off the reaction mixture and washed troughly with dichloromethane. Workup was then performed. The crude product was purified by flashchromatography (eluent: petrol ether $\left(40^{\circ} \mathrm{C}-60^{\circ} \mathrm{C}\right)$ :diethyl ether, $50 \%$ ) and enantioselectivity of epoxide was 
measured by $400 \mathrm{MHz}$ NMR using chiral Eu(hfc) $)_{3}$-reagent (as acetates).

\section{(2S-trans)-3-Propyloxiranemethanol (6)}

The epoxidation was performed as described above. $\mathrm{C}_{8}$ poly(tartrate ester) 4 (2.6 g, $0.01 \mathrm{~mol})$ was swelled in 40 ml of $\mathrm{CH}_{2} \mathrm{Cl}_{2}$ containing $0.3 \mathrm{~g}$ of powdered, activated $4 \AA$ molecular sieves. $\mathrm{Ti}\left(\mathrm{OPr}^{\mathrm{i}}\right)_{4}(1.42 \mathrm{~g}, 0.005 \mathrm{~mol}), 12.5 \mathrm{ml}$ of a 3.2 M solution of TBHP in iso-Octane and $2 \mathrm{~g}(0.02 \mathrm{~mol})$ of trans-hex-2-en-1-ol (dissolved in $10 \mathrm{ml} \mathrm{CH}_{2} \mathrm{Cl}_{2}$ ) were added. The reaction mixture was stirred at $-20{ }^{\circ} \mathrm{C}$ for $6 \mathrm{~h}$ and stored at $-20{ }^{\circ} \mathrm{C}$ overnight. Polymer was filtered off and washed throughly with $\mathrm{CH}_{2} \mathrm{Cl}_{2}$. Workup was then performed and crude product was purified by flashchromatography (eluent: petrol ether $\left(40^{\circ} \mathrm{C}-\right.$ $\left.60^{\circ} \mathrm{C}\right)$ :diethyl ether, $\left.50 \%\right)$ to give colourless oil $(1.22 \mathrm{~g}$, $53 \%$ yield, $100 \%$ purity, $87 \%$ ee by ${ }^{1} \mathrm{H}$ NMR analysis of the derived acetate with $\left.\operatorname{Eu}(\mathrm{hfc})_{3}\right):[\alpha]^{25}{ }_{\mathrm{D}}-38^{\circ}(c$ 2.01, $\mathrm{CHCl}_{3}$ ), GC analysis before work-up: $78 \%$ epoxide. FTIR $\left(\mathrm{CHCl}_{3}\right)$ 2977, 2952, 1717, 1457, 1237, 1196, 933, 881, 806, 796. ${ }^{1} \mathrm{H}$ NMR $\left(200 \mathrm{MHz}, \mathrm{C}_{6} \mathrm{D}_{6}\right) \delta 3.72$ (ddd, $J=3,6$, $12 \mathrm{~Hz}, 1 \mathrm{H}), 3.46$ (ddd, $J=5,7,12 \mathrm{~Hz}, 1 \mathrm{H}), 2.79-2.85$ (m, $1 \mathrm{H}), 2.70-2.74(\mathrm{~m}, 1 \mathrm{H})$, ), $2.33(\mathrm{t}, J=6 \mathrm{~Hz}, 1 \mathrm{H}), 1.34-1.45$ $(\mathrm{m}, 4 \mathrm{H}), 0.93(\mathrm{t}, J=7 \mathrm{~Hz}, 3 \mathrm{H}) . \mathrm{MS}(\mathrm{EI}, \mathrm{m} / \mathrm{z}$, relative intensity) $99(0.8, \mathrm{M}-17)^{+}, 81$ (7), 73 (20), 61 (8), 55 (100), 43 (86). HRMS (EI) Calcd for $\mathrm{C}_{6} \mathrm{H}_{12} \mathrm{O}_{2}$ 116.0837, found 116.0882 .

Acknowledgement: J.K.Karjalainen is grateful to the Neste Oy's Foundation for receiving financial support. She also thanks Ms L. Canali from the University of Strathclyde for performing the HPLC-measurements.

\section{References}

1. (a) Sherrington, D. C. Polymer-supported Synthesis in Chemistry of Waste Minimisation; Ed. J. H. Clark: Blackie Publishers, 1995; Chap.6. pp 141-196. (b) Hodge, P. Polymer-supported Asymmetric Organic Synthesis in Innovation and Perspectives in Solid Phase Synthesis; Ed. R. Epton; SPCC UK, 1990; pp 273-292.

2. (a) Pini, D.; Petri, A.; Nardi, A.; Rosini, C.; Salvadori, P. Tetrahedron Lett. 1991, 32, 5175-5178. (b) De, B. B.; Lohray, B. B.; Sivaram, S.; Dhal, P. K. Tetrahedron Asymm. 1995, 6, 2105-2108. (c) Minutolo, F.; Pini, D; Salvadori, P. Tetrahedron Lett. 1996, 37, 3375-3378.

3. See ref. 2. (a) Kim, B. M.; Sharpless, K. B. Tetrahedron Lett. 1990, 31, 3003-3006. (b) Jacobsen, E. N.; Zhang, W.; Muci, J. R.; Echer, J. R.; Deng L. J. Am. Chem. Soc. 1991, 113, 7063-7064. (c) Lohray, B. B.; Thomas, A.; Chittari, P.; Ahuja, J. R.; Dhal, P. K. Tetrahedron Lett. 1992, 33, 5453-5456. (d) Pini,
D.; Petri, A.; Salvadori, P. Tetrahedron Asymm. 1993, 4, 2351-2354. (e) Itsuno, S.; Koizumi, T.; Okumura, C.; Ito, K. Synthesis 1995, 150-152. (f) Han, H.; Janda, K. D. J. Am. Chem. Soc. 1996, 118, $7632-7633$.

4. (a) Farrall, M. J. F.; Alexis, M.; Trecarten, M. Nouv. J. de Chimie 1983, 7, 449-451. (b) Choudary, B. M.; Valli, V. L. K.; Prasad, A.D. J. Chem. Soc. Chem. Comm. 1990, 1186-1187.

5. Canali, L.; Karjalainen, J. K.; Hormi, O.; Sherrington, D. C. J. Chem. Soc. Chem. Comm. 1997, 123-124.

6. Karjalainen, J. K.; Hormi, O.; Sherrington, D. C. Submitted.

7. Stevens, M.P. Polymer Chemistry an Introduction; $2^{\text {nd }}$ Ed., Oxford University Press, 1990; pp 392-417.

8. Polymer samples were dissolved in hot $\mathrm{Me}_{2} \mathrm{SO}$. The ${ }^{1} \mathrm{H}$ and ${ }^{13} \mathrm{C}$ NMR spectra were obtained on $400 \mathrm{MHz}$ spectrometer at $343 \mathrm{~K}$. The used polymer batches did not contain any charasteristic branching/crosslinking methine signals according to ${ }^{1} \mathrm{H}$ NMR spectra. Some polymer batches contained toluene- $p$-sulfonic acid.

9. General method to synthesise polyesters was followed with slight modifications. Seebach, D.; Kalinowski, H.-O.; Langer, G.; Grass, G.; Wilka, E. M. Organic Synthesis, 1983, 61, 24.

10. General phase transfer catalysis method was used in polymer synthesis. March, J. Advanced Organic Chemistry; $3^{\text {rd }}$ Ed, J. Wiley and Sons, New York, 1985; pp 353.

11. Aldrich Handbook of Fine Chemicals, 1994-1995: dimethyl-L-(+)-tartrate: $[\alpha]_{\mathrm{D}}^{22}+21^{\circ}\left(c 2.5, \mathrm{H}_{2} \mathrm{O}\right)$ and diethyl-L-(+)-tartrate: $[\alpha]_{\mathrm{D}}^{20}+8.5^{\circ}$ (neat).

12. $[\alpha]_{\mathrm{D}}^{25}+9(c 1.6, \mathrm{THF})$.

13. No attempt was made to re-precipitate and re-use these polymers.

14. Augustine, R.L. Heterogeneous Catalysis for the Synthetic Chemist; Marcel Dekker, Inc., New York, 1996; pp 7-11.

15. Sharpless catalytic method for asymmetric epoxidation was followed with slight modifications. Gao, Y.; Hanson, R. M.; Klunder, J. M.; Ko, S. Y.; Masamune, H.; Sharpless, K. B. J. Am. Chem. Soc. 1987, 109, 5765-5780.

16. Johnson, R. A.; Sharpless, K. B. In Catalytic Asymmetric Synthesis; Ed. Ojima, I., VCH Publishers, Inc., 1993; pp 103-158.

17. The reaction mixtures were kept at $-20^{\circ} \mathrm{C}$ overnight since it was observed that reactions continued slowly also without strirring. However, this procedure did not have any effect on lower/higher enantioselectivity.

18. Maud, J. M. Solid Supports and Catalysts in Organic Synthesis, Ed. Smith K., Ellis Horwood limited, England, 1992, pp 40-58. 
19. (a) Finn, M. G.; Sharpless, K. B. In Asymmetric Synthesis; Ed. Morrison, J. D., Academic Press, Orlando, FL, vol.5, 1985; pp 247-301. (b) Finn, M. G.; Sharpless, K. B. J. Am. Chem. Soc. 1991, 113, 113-126.
20. The research on development of the reusable heterogeneous epoxidation catalyst is under the investication in our laboratory.

21 Hill, J. G.; Rossiter, B. E.; Sharpless, K. B. J. Org. Chem. 1983, 48, 3607-3608.

Sample Availability: available from the authors. 